\title{
Positioning Surgery at the Core of the Universal Health Coverage Agenda
}

\author{
Aruyaru Stanley Mwenda \\ Consolata Hospital Mathari, Nyeri
}

Correspondence to: Aruyaru Stanley Mwenda, PO Box 268-10100, Nyeri; email: arumwesta@gmail.com

Ann Afr Surg. 2019; 16(2):49-50

DOI:http://dx.doi.org/10.4314/aas.v16i2.1

Key words: Universal Health Coverage, Surgical

Forty years ago, over 3,000 global health experts converged in a city in present day Kazakhstan to chart the way forward on matters public health. At the conclusion, the delegates would adopt 10 key resolutions dubbed The Alma Ata Declaration (1).

The Alma Ata Declaration was a giant leap for public health, but it was never to be even a small step for surgery. And so for years, surgery was consigned to the periphery of the global public health agenda (2). Surgery was erroneously deemed 'too expensive, too sophisticated/specialized and not appropriate for public health initiatives' (2), even when statistics emerged showing that surgery was responsible for a significant portion of the global burden of disease (3). Farmer and Kim would, years after Alma Ata, aptly describe surgery as the neglected step-child of global public health (4).

However, recent developments have provided a rare opportunity for us to position surgery at the core of the global public health agenda.

First, the 68th World Health Assembly adopted resolution WHA 68.15 which called for strengthening emergency and essential surgery and anaesthesia as components of Universal Health Coverage (UHC) (2). As a result, several low and low-middle income countries (LMICs) are in a race to develop national surgical obstetric and anaesthesia plans. Indeed, this is a step in the right direction.

Second, the Kenyan government has adopted UHC as one of the top 4 agenda items for the 2017-2022 governance cycle (5).

These developments herald a new opportunity for us all to push for surgery to be at the core of the UHC agenda in our region. We have previously argued in these editorial pages about the role of the surgeon as an advocate (6). The time is nigh for us all to take up that advocacy role individually and as associations.

The papers in this issue remind us of the work that lies ahead. We still struggle with congenital (7) and infectious surgical diseases (8) that are competing for the same surgical services in a world where non-communicable advocacy, Health financing, Surgery, Trauma

Conflicts: None

Funding: None

diseases are the new frontier. Trauma still remains a significant cause of surgical morbidity and mortality. Tellingly, nearly all (90\%) of trauma-related deaths occur in the LMICs (9).

UHC means that we provide quality health servicespreventive, promotive, curative, rehabilitative and palliative - as needed by our populations while offering them financial protection (10). Nnabugwu et al. (11) give insights into the challenge of financing surgery based on a household's financial capability. Out-of-pocket payment for surgery places many households at risk of catastrophic or impoverishing health expenditure. For UHC to be achieved, it is imperative that surgery is financed through a health insurer. Wanjau has previously described what should be done for a national health insurance to adequately finance surgical services (12).

The challenges may seem overwhelming but the opportunity at hand is unparalleled. It is not an everyday occurrence for example to see both a president and first lady who have health care as their top priority, as is the case in Kenya. It is now up to the surgeon to make sure that surgery permeates the UHC priority list, at the top there where malaria, tuberculosis and HIV and AIDS have held the fort. Research shows that of the 100 million people who suffer injuries globally every year, 5 million die - more than the deaths from malaria, tuberculosis and HIV and AIDS combined(2)! We have enough data to back us up. It is now time to act.

Among the things we need to do as individuals is TALK. Talk about surgery every time. Talk about surgery financing to our patients, they might know someone influential. Talk about surgery financing to our business associates, they might be friends of the political leaders. As surgical associations, let us make our stands official. Official stands on everything that affects surgery be it legislation or financing, training or staffing. When we all speak in one voice there is no other option but to be heard. As things stand, the stars could never have aligned better for us to push surgery to the core of the UHC agenda. 


\section{References}

1. World Health Organization (1978). AlmaAta Declaration. Available: https://www.who.int/publications/almaata declaration en.pdf. Accessed 14 July 2019.

2. Price R, Makasa E, Hollands M. World Health Assembly Resolution WHA68.15: Strengthening Emergency and Essential Surgical Care and Anesthesia as a Component of Universal Health Coverage-Addressing the Public Health Gaps Arising from Lack of Safe, Affordable and Accessible Surgical and Anesthetic Services. World J Surg. 2015; 39(9): 2115-25.

3. Shrime MG, Bickler SW, Alkire BC, Mock C. Global burden of surgical disease: An estimation from the provider perspective. Lancet 2015; 3(52):s8-9.

4. Farmer PE, Kim JY. Surgery and global health: A view from beyond the OR. World J Surg. 2008; 32(4):533-536

5. The Presidency (2016). The Big Four. Available: https:// big4.delivery.go.ke/ Accessed 14 July 2019.

6. Mwenda AS, Mwachiro MD. The surgeon and advocacy. Ann Afr Surg. 2015; 12(1):1-2.

7. Jumbi T, Swaleh S, Mugo R, et al. Risk factors for urethrocutaneous fistula development after hypospadia surgery. Ann Afr Surg. 2019; 16(2):59-63.
8. Hamid M, Ahmed S, Jamil A, et al. Allergic fungal rhinosinusitis caused by Aspergillus flavus. Ann Afr Surg. 2019; 16(2):75-77.

9. Stewart KA, Groen RS, Kamara TB, et al. Traumatic injuries in developing countries: Report from a nationwide cross-sectional survey of Sierra Leone. JAMA Surg. 2013; 148(5):463-469

10. World Health Organization (2019). Universal Health Coverage. Available: https://www.who.int/ healthsystems/universal_health_coverage/en/Accessed 14 July 2019.

11. Nnabugwu II, Nwankwor C, Ugwumba F. Gaining access to major elective surgeries in a public tertiary health institution in southeast Nigeria: Evaluating household payment coping strategies. Ann Afr Surg. 2019; 16(2):69-74.

12. Wanjau W. Reforming the National Hospital Insurance Fund for better surgical care financing. Ann Afr Surg. $2019 ; 16(1): 1-3$. 